\title{
Dynamic Mechanical Absorptions Observed for Regenerated Cellulose Solids in the Temperature Range from 280 to $600 \mathrm{~K}$
}

\author{
Sei-ichi Manabe, Michitaka IwatA, and Kenji KAMIDE \\ Fundamental Research Laboratory of Fibers and Fiber-Forming Polymers, \\ Asahi Chemical Ind. Co., Ltd., Hacchonawate 11-7, \\ Takatsuki, Osaka 569, Japan
}

(Received February 6, 1985)

\begin{abstract}
An attempt was made to establish the mechanism of the dynamic mechanical absorption phenomena of regenerated cellulose solids observed in the temperature range between 280 and $600 \mathrm{~K}$ at a frequency of $110 \mathrm{~Hz}$. For the purpose, isochronal dynamic viscoelasticities of regenerated cellulose fibers and membranes were measured by dynamic modulus, loss modulus, and dynamic loss tangent in air at a heating rate of $12 \mathrm{~K} \mathrm{~min}^{-1}$ or in various kinds of liquid medium at $3 \mathrm{~K} \mathrm{~min}^{-1}$. Three absorption peaks, $\alpha_{1}, \alpha_{2}$, and $\alpha_{\mathrm{H}_{2} \mathrm{O}}$, and one absorption shoulder, $\alpha_{\mathrm{sh}}$, were observed near $573,513,303$, and $393 \mathrm{~K}$, respectively. The content of water absorbed in the sample was closely related to the appearance of the $\alpha_{\mathrm{H}_{2} \mathrm{O}}$ absorption which was due to the cooperative motion of polymer segment and absorbed water molecules. The dependence of the viscoelasticity on temperature and frequency revealed that the $\alpha_{2}$ absorption consisted of two $\alpha_{\mathrm{a}}$ absorptions, $\alpha_{2,1}$ and $\alpha_{2,2}$, whose apparent activation energies were 289 and $209 \mathrm{kJmol}^{-1}$, respectively. All of the $\alpha_{1}, \alpha_{2,1}$, $\alpha_{2,2}$, and $\alpha_{\mathrm{sh}}$ absorptions originated from the micro-Brownian motion of polymer segments in the amorphous region. The temperatures of these four absorptions were dominated by the segmental environment such as the density of intermolecular hydrogen bonding.

KEY WORDS Regenerated Cellulose / Dynamic Mechanical Absorption / Viscoelasticity / Glass Transition / Hydrogen Bonding / MicroBrownian Motion / Activation Energy / Heat-Treatment / Water Absorption /
\end{abstract}

The study of the complicated supermolecular structure of the regenerated cellulose solid still remains in a rather primitive state despite of its necessity and importance in modern cellulose industry. The structural complexity undoubtedly originates from the existence of a wide variety of the intra- and intermolecular hydrogen bondings in the cellulose solid. ${ }^{1}$ For example, the degree of crystallinity obtained for a given regenerated cellulose solid is not always the same, but depends significantly on the method of measurements employed. ${ }^{2}$ This fact suggests that the so-called amorphous region is heterogeneous with respect to the density or regularity of polymer chains in the aggregated state. The dependence of the reaction rate of chemical reagents on the supermolecular structure of cellulose solid has been widely recognized and has been utilized as a method for evaluating the lateral order of the regenerated cellulose fibers. ${ }^{3}$ However, the supermolecular structure other than the lateral order has not been evaluated.

Recently, we established a method for estimating the distribution of the packing density of polymer chains belonging to an amorphous region in semi-crystalline solid by analyzing the dynamic loss tangent $(\tan \delta)$ vs. temperature curve. ${ }^{4-8}$ In order to apply this method successfully to a given polymer, the mechanism of all the dynamic absorptions should be clarified. Furthermore, the profile of $\tan \delta$ should be given in advance in the temperature range where the micro-Brownian mo- 
tion of polymer chains are conspicuous.

The viscoelastic properties of natural and regenerated cellulose solids have so far been studied mostly at lower temperatures than $523 \mathrm{~K}$, for the chemical degradation takes place at higher temperatures when the samples are heated at a slow rate as $1 \mathrm{~K} \mathrm{~min}^{-1}$. The dynamic mechanical absorptions originating from the micro-Brownian motion of cellulose chains in the amorphous region (hereafter denoted as $\alpha_{\mathrm{a}}$ absorption) have not so far been clearly identified experimentally. The glass transition temperature, $T_{\mathrm{g}}$, or the second order transition temperature has been determined from the temperature dependence of the specific volume or specific heat and is expected to be located near the peak temperature, $T_{\text {max }}$, of the $\tan \delta$ curve for the $\alpha_{\mathrm{a}}$ absorption.

The glass transition temperature of cellulose solids found in literature lies between $243 \mathrm{~K}$ (by dilatometry) and $423 \mathrm{~K}$ (by differential scanning calorimetry, DSC). ${ }^{9-17}$ Kubat and Pattyramie ${ }^{9}$ observed a transition at $243 \mathrm{~K}$ by dilatometry and stress relaxation for regenerated cellulose fibers. Hatakeyama and Kanetsuna $^{13}$ determined $T_{\mathrm{g}}$ by DSC to be $358 \mathrm{~K}$ for linter cellulose and $328 \mathrm{~K}$ for socalled amorphous cellulose prepared by saponification of cellulose triacetate. Ramiah and Goring $^{14}$ observed by dilatometry three transitions at about 298 and $383 \mathrm{~K}$ for Avory cellulose, and at about 298 and $513 \mathrm{~K}$ for sulfite pulp cellulose. They concluded that the transition near $298 \mathrm{~K}$ was due to the breakage of weak hydrogen bondings and that the transition at $383 \mathrm{~K}$ was attributable to motions of a restricted segment of the chain. On the other hand, the transition at $513 \mathrm{~K}$ was assigned as the softening temperature or the glass transition temperature in a narrow sense. From the Nakamura's data ${ }^{15,16}$ on $T_{\mathrm{g}}$ for cellulose acetate by dilatometry and viscoelastic measurements, we can estimate the $T_{\mathrm{g}}$ of cellulose solid to be $507 \mathrm{~K}$. Very recently Kamide and Saito ${ }^{17}$ have found by DSC that the $T_{\mathrm{g}}$ of cellulose acetates can be represented as a function of the total degree of substitution, $\langle\mathrm{F}\rangle$, in the form,

$$
T_{\mathrm{g}}=523-20.3\langle\mathrm{~F}\rangle
$$

From this relation, $T_{\mathrm{g}}$ for the unsubstituted cellulose is estimated to be $523 \mathrm{~K}$ by the extrapolation that $\langle\mathrm{F}\rangle=0$. If $503 \leq T_{\mathrm{g}} \leq 523 \mathrm{~K}$ is acceptable, it seems reasonable that the $\alpha_{a}$ absorption can not be experimentally observed by the viscoelastic experiment below $523 \mathrm{~K}$.

The aim of the present article is to investigate the dynamic absorptions of regenerated cellulose solid locating in the temperature range from 280 to $600 \mathrm{~K}$ by using a high rate of heating (i.e., $12 \mathrm{~K} \mathrm{~min}^{-1}$ ) or by using a conventional rate of heating (i.e., $1 \mathrm{~K} \mathrm{~min}^{-1}$ ) and also by adding the solvents which make the dynamic absorptions shift to a lower temperature.

\section{EXPERIMENTAL}

\section{Polymers}

Regenerated cellulose fibers and membranes utilized are designated as follows. Four commercially available cuprammonium cellulose fibers, Bemberg ${ }^{\circledR}$, were denoted by B1, B2, B3, and B4 which were manufactured by Asahi Chemical Industry Co., Ltd., Japan, and specified as 75 denier/36 filament, i.e., a fiber consisted of 36 filaments and the linear density of single fiber was $8.5 \times 10^{-5} \mathrm{~g} \mathrm{~cm}^{-1}$. The viscose rayon fiber denoted by $\mathrm{R} 1$ was also a 75 denier/36 filament manufactured by Asahi Chemical Industry Co., Ltd., Japan. A series of Bemberg fibers, $\mathrm{H}_{468}, \mathrm{H}_{493}, \mathrm{H}_{513}, \mathrm{H}_{535}$ and $\mathrm{H}_{548}$, were obtained by heat-treatment of B2 at indicated temperatures between 468 and $548 \mathrm{~K}$ in nitrogen atmosphere under a fixed length for $1 \mathrm{~h}$. The tublar cuprammonium cellulose membrane, $\mathrm{T} 1$, was cast in our laboratory according to the procedure described in the patent literature. ${ }^{18}$ Four porous plain cellulose membranes, T2, T3, T4, and $\mathrm{T} 5$, and six hollow fibers, $\mathrm{BH} 1, \mathrm{BH} 2, \mathrm{BH} 3$, $\mathrm{BH} 4, \mathrm{BH} 5$, and $\mathrm{BH} 6$, were prepared in our laboratory from cellulose cuprammonium 
solution by adding acetone or sodium hydroxide as coagulating reagents. ${ }^{19}$ Here, acetone gave the regenerated cellulose with extremely low crystallinity, while sodium hydroxide gave the cellulose with relatively high crystallinity.

The relative humidity $\mathrm{RH}$ of the atmosphere was controlled to $100,80,67$, and $60 \%$ at $303 \mathrm{~K}$ using various aqueous solutions saturated with salts.

\section{Solvents}

Following solvents were used as immersing media during measurements of the viscoelastic properties: ethylene glycol, diethylene glycol, triethylene glycol, poly(ethylene glycol) (molecular weight; 200, 400, 600, and 800) and glycerine. All of these were of guaranteed reagent grade manufactured by Kishida Chemical Co., Ltd., Osaka.

\section{Measurements}

Temperature dependences of dynamic modulus $E^{\prime}$, loss modulus $E^{\prime \prime}$, and $\tan \delta$ were measured by using a direct reading viscoelastometer, Rheovibron DDV-IIc (manufactured by Toyo-Boldwin Co., Ltd., Japan), under the following conditions. Sample weight was $c a$. $0.5 \mathrm{mg}$, frequency $f$ was $110 \mathrm{~Hz}$ and average heating rate was $12 \mathrm{~K} \mathrm{~min},{ }^{-1}$ if not specifically indicated. The sample was stored in a desiccator with silica gel for more than $72 \mathrm{~h}$ in advance of measurement.

The apparent activation energy for the $\alpha_{\mathrm{a}}$ dynamic absorption, $\Delta H_{\mathrm{a}}$, was determined from the frequency dependence of the peak temperature, $T_{\max }$, of $\tan \delta$ or $E^{\prime \prime}$ using the following equation

$$
\Delta H_{\mathrm{a}}=-R \frac{\mathrm{d} \ln f}{\mathrm{~d}\left(1 / T_{\max }\right)}
$$

where $R$ is the gas constant. The frequencies used in the determination of $\Delta H_{\mathrm{a}}$ were 110,11 , and $3.5 \mathrm{~Hz}$. The relative humidity of atmosphere in the vessel for sample storage was controlled with great care by putting the sam- ples above saturated aqueous salts. In order to measure $E^{\prime}, E^{\prime \prime}$, and $\tan \delta$ of cellulose solid immersed in a liquid medium as functions of temperature, the system of the test polymer and liquid was placed in the inner hollow of a cuprammonium hollow fiber as illustrated in Figure 1. The hollow fiber was prepared in our laboratory for this purpose. The detailed procedure has already been described before. ${ }^{20}$

Both the apparent crystal size, $\left[L_{h k l}\right]$ and the degree of crystal orientation, $O_{h k l}$ were measured by X-ray diffractometry, where the suffix $h k l$ means that $L$ or $O$ was determined along the crystal direction with Miller indexes $h k l$. The X-ray generator used was a rotor unit type of target (manufactured by Rigaku Denki Co., Ltd., Japan, "RU-200P/L”). The incident Xray beam was of monochloric $\mathrm{Cu}-K_{\alpha}$ line filtered by a set of $\mathrm{Ni}$ filter, and a sintiration counter was employed. The width of a divergence slit and a horizontal slit was 1 degree. After fixing the preselected diffraction angle $2 \theta$, the X-ray diffraction intensity along with azimuthal direction was recorded by rotating the specimen holder in the plane of the sample. $L_{h k l}$ and $O_{h k l}$ were calculated by using eq 2 and 3 , respectively;

$$
\begin{aligned}
& L_{h k l} \text { (in nm unit) }=k \lambda / \beta \cos \theta \\
& O_{h k l}(\text { in } \%)=[(180-H) / 180] \times 100
\end{aligned}
$$

where $\lambda$ was the wave length of $X$-ray $(=0.1541 \mathrm{~nm}), \quad k$ the apparatus constant $(=1.0), \beta$ the half value width in radian of the $\mathrm{X}$-ray diffraction intensity $(I) v s .2 \theta$ curve and $H$ the half value width in degree of the curve of $I v s$. azimuthal angle. It has been experimenttally confirmed for the regenerated celluloses that both $O_{10 \overline{1}}$ and $O_{002}$ of fibers except for the hollow fiber have approximately the linear relation against the orientation function parameter, $F_{\mathbf{b}}$, of the $b$ axis, which is defined by $F_{\mathrm{b}}=\left[3\left(\overline{\cos ^{2} \phi}\right)-1\right] / 2$. Here $\phi$ represents the angle between the fiber axis and $b$ axis of the cellulose II crystal, and the bar represents the mean value. 
(a)

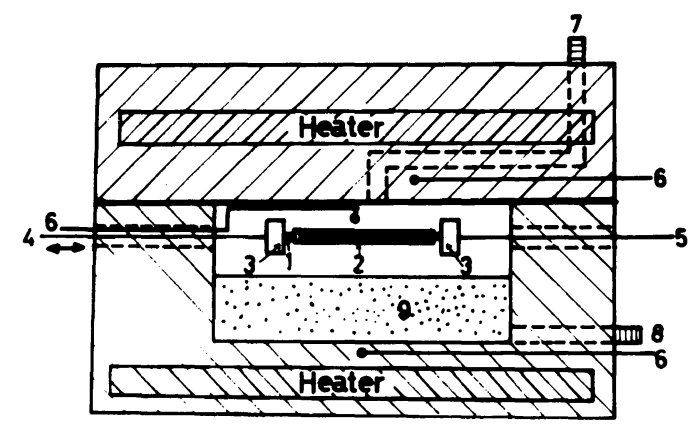

(b)

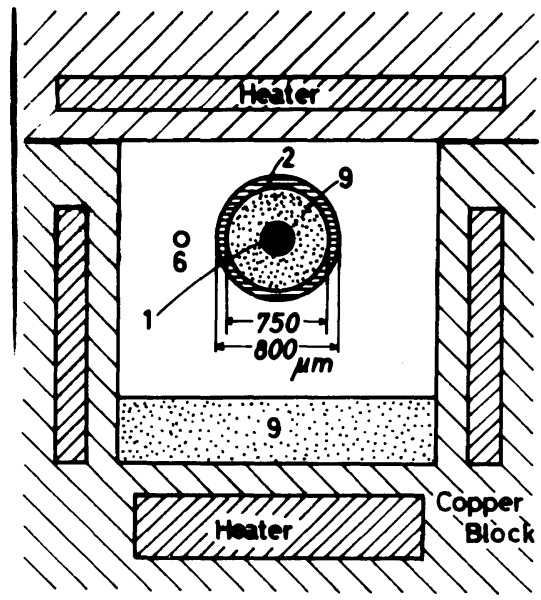

Figure 1. Schematic representation of the cross sectional view of the chamber for measuring the dynamic viscoelasticities in the liquid: (a), longitudial cross sectional view; (b), side cross sectional view; 1, sample; 2 , regenerated cellulose hollow fiber with inner diameter of $750 \mu \mathrm{m}$ and outer diameter of $800 \mu \mathrm{m} ; 3$, sample holder; 4, strain inducer rod; 5 , stress detection rod; 6 , thermocouple; 7 , inlet of liquid; 8 , outlet of liquid; 9 , immersing liquid.

$$
\begin{aligned}
F_{\mathrm{b}} \simeq & 2.27 \times 10^{-2} O_{10 \overline{1}}-1.5 \\
& \text { when } O_{10 \overline{1}}>60 \% \\
F_{\mathrm{b}} \simeq & 1.30 \times 10^{-2} O_{002}-0.65 \\
& \text { when } O_{002}>60 \%
\end{aligned}
$$

Therefore, $F_{\mathrm{b}}$ can be evaluated from $O_{10 \overline{1}}$ or $\mathrm{O}_{002}$ data, if necessary. Applicability of eq 4 and 5 can be confirmed by comparing $O_{002}$ and $O_{10 \overline{1}}$, which are expected to satisfy the relation: $O_{002} \simeq 1.75 O_{10 \overline{1}}-5.77$.

The refractive indexes of the light whose electric field vectors oscillate parallel and perpendicular to the fiber axis (or the drawing direction for membrane), $n_{\|}$and $n_{\perp}$, were measured by an interference microscope (manufactured by Karl Zweis Jena Co., "Interphako") with the wave length of an incident light $\lambda=546 \mathrm{~nm}$. Here, the regenerated cellulose fibers and membranes were immersed in a binary liquid mixture of $\alpha$ bromonaphthalene and olive oil or in that of $\alpha$ bromonaphthalene and diiodomethane, in which the refractive index was carefully adjusted to match with that of the cellulose sample. From $n_{\|}$and $n_{\perp}$ thus determined, the mean refractive index $n_{\text {iso }}\left(\equiv\left(n_{\|}+2 n_{\perp}\right) / 3\right)$ and the birefringence $\Delta n\left(\equiv n_{\|}-n_{\perp}\right)$ were estimated.

As well-known, ${ }^{22} n_{\text {iso }}$ is linearly proportional to the density and the density shows a linear dependence on the crystallinity $\chi_{c}$. Then, we obtain eq $6^{21}$

$$
\begin{aligned}
& \chi_{\mathrm{c}}=\left[n_{\text {iso }}-n_{\text {iso }}\left(\chi_{\mathrm{c}}=0 \%\right)\right] / \\
& \quad\left[n_{\text {iso }}\left(\chi_{\mathrm{c}}=100 \%\right)-n_{\text {iso }}(\chi=0 \%)\right]
\end{aligned}
$$

where $n_{\text {iso }}\left(\chi_{\mathrm{c}}=0 \%\right)$ and $n_{\text {iso }}\left(\chi_{\mathrm{c}}=100 \%\right)$ are the values for ideal amorphous solid $\left(\chi_{\mathrm{c}}=0 \%\right)$ and crystalline states $\left(\chi_{\mathrm{c}}=100 \%\right)$, respectively. These two quantities can not be directly evaluated by experiments because of the difficulty of preparing the samples of $\chi_{c}=0 \%$ and $100 \%$. Thus, these were only indirectly estimated in such a manner that the $\chi_{c}$ calculated from observed values of $n_{\text {iso }}$ for a widest variety of test samples should lie between 0 and $100 \%$. The values of $n_{\text {iso }}\left(\chi_{\mathrm{c}}=0 \%\right)$ and $n_{\text {iso }}\left(\chi_{\mathrm{c}}=100 \%\right)$ thus obtained are 1.5077 and 1.5533, respectively. Equation 6 can be rewritten for the regenerated celluloses in the form. ${ }^{21}$

$$
\chi_{\mathrm{c}}=\left(n_{\mathrm{iso}}-1.5077\right) / 0.0456
$$


Table I. Structural parameters of regenerated cellulose solids

\begin{tabular}{|c|c|c|c|c|c|}
\hline \multirow{2}{*}{ Sample code } & \multicolumn{2}{|c|}{ Apparent crystal size } & \multirow{2}{*}{$\begin{array}{c}\text { Crystal orientation } \\
\text { function parameter, } F_{\mathrm{b}}\end{array}$} & \multirow{2}{*}{$\begin{array}{l}\text { Birefringence, } \\
\Delta n\end{array}$} & \multirow{2}{*}{$\begin{array}{c}\text { Crystallinity, } \\
\chi_{\mathrm{c}} / \%\end{array}$} \\
\hline & $L_{10 \overline{1}} / \mathrm{nm}$ & $L_{002} / \mathrm{nm}$ & & & \\
\hline B1 & 4.00 & 4.81 & 0.49 & 0.0338 & 54.4 \\
\hline B2 & 2.73 & 3.55 & 0.47 & 0.0375 & 48.2 \\
\hline B3 & 3.41 & 4.18 & 0.53 & 0.0368 & 55.5 \\
\hline B4 & 3.44 & 3.79 & 0.45 & 0.0346 & 54.4 \\
\hline $\mathrm{H}_{468}$ & 2.73 & 3.54 & 0.47 & 0.0376 & 48.9 \\
\hline $\mathrm{H}_{493}$ & 2.75 & 3.55 & 0.47 & 0.0374 & 49.3 \\
\hline $\mathrm{H}_{513}$ & 2.78 & 3.57 & 0.47 & 0.0379 & 50.0 \\
\hline $\mathrm{H}_{535}$ & 2.78 & 3.58 & 0.48 & 0.0381 & 50.9 \\
\hline $\mathrm{H}_{548}$ & 2.80 & 3.65 & 0.48 & 0.0386 & 52.2 \\
\hline $\mathrm{R} 1$ & 2.71 & 3.35 & 0.44 & 0.0380 & 57.7 \\
\hline $\mathrm{T} 1$ & 2.69 & 3.06 & 0.05 & 0.00 & 47.4 \\
\hline $\mathrm{T} 2$ & $<2.0$ & $<2.0$ & $0.03^{\mathrm{a}}$ & 0.00 & 0.7 \\
\hline T3 & 2.10 & 2.90 & $0.04^{\mathrm{a}}$ & 0.00 & 10.1 \\
\hline $\mathrm{T} 4$ & $<2.0$ & $<2.0$ & $0.01^{\mathrm{a}}$ & 0.00 & 0.4 \\
\hline T5 & $<2.0$ & $<2.0$ & $0.02^{\mathrm{a}}$ & 0.00 & 0.9 \\
\hline BH1 & 2.68 & 3.10 & 0.25 & 0.0170 & 48.2 \\
\hline BH2 & 2.60 & 3.24 & 0.31 & 0.0342 & 50.0 \\
\hline $\mathrm{BH} 3$ & 2.50 & 3.12 & 0.26 & 0.0180 & 48.9 \\
\hline BH4 & $<2.0$ & 2.70 & $0.08^{\mathrm{a}}$ & 0.0100 & 11.1 \\
\hline BH5 & $<2.0$ & $<2.0$ & $0.01^{\mathrm{a}}$ & 0.0090 & 1.3 \\
\hline BH6 & $<2.0$ & $<2.0$ & $0.02^{\mathrm{a}}$ & 0.0020 & 1.0 \\
\hline
\end{tabular}

a Apparent value evaluated from the half value width of X-ray intensity $v s$. azimuthal angle curve.

This equation allows us to evaluate $\chi_{\mathrm{c}}$ from $n_{\text {iso }}$.

\section{RESULTS AND DISCUSSION}

Table I summarizes $L_{10 \overline{1}}, L_{002}, F_{\mathrm{b}}, \Delta n$, and $\chi_{\mathrm{c}}$ of all regenerated cellulose solids. The samples of the series $\mathrm{B}$ and $\mathrm{H}$ have relatively high $\chi_{\mathrm{c}}$ values, and most samples of the $\mathrm{T}$ and $\mathrm{BH}$ series show low crystal orientation.

Figure 2 shows the temperature dependence of isochronal dynamic viscoelasticity $\left(E^{\prime}\right.$ and $\tan \delta$ ) for sample B1. Three peaks are observed in the $\tan \delta v s$. temperature curves at about 570,510 , and $300 \mathrm{~K}$. These are named tentatively as the $\alpha_{1}, \alpha_{2}$, and $\alpha_{3}$ absorptions from higher temperature side. In addition to these absorptions a small shoulder can be detected

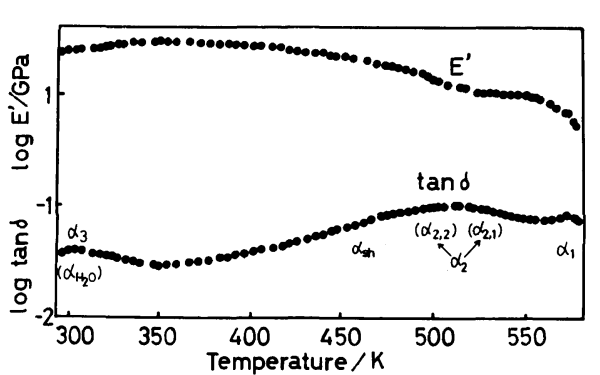

Figure 2. Temperature dependence of $\tan \delta$ and $E^{\prime}$ for sample code B1 $(110 \mathrm{~Hz})$.

near $460 \mathrm{~K}$ and is denoted as $\alpha_{\mathrm{sh}}$. All the four absorptions are observed for the samples of the series of $\mathrm{B}, \mathrm{H}, \mathrm{R}$, and the samples of $\mathrm{T} 1, \mathrm{BH} 1$, $\mathrm{BH} 2$, and $\mathrm{BH} 3$. These samples have relatively high $\chi_{\mathrm{c}}$ more than $47 \%$ without exception. It may be reasonable to assume that the differ- 
ence between moduli at $510 \mathrm{~K}$ and $580 \mathrm{~K}$, $E^{\prime}(510)-E^{\prime}(580)$, represents the relaxation intensity of the $\alpha_{1}$ absorption at $570 \mathrm{~K}$. The relaxation intensity thus obtained is of order of $10 \mathrm{GPa}$, though the $\tan \delta$ peak relating the absorption at $570 \mathrm{~K}$ is of order of only 0.08 or less. This small peak value suggests that there must be some amount of the polymer segment being immobile at the $\alpha_{1}$ absorption such as ones in crystalline region. The existence of such segment will be ascertained in the later section by measuring $E^{\prime}$ of the sample immersed in water at $323 \mathrm{~K}$ (see Figure 12a).

The change in $E^{\prime}$ and the $\tan \delta$ peak relating to the $\alpha_{2}$ absorption are estimated to be $c a .20$ GPa $\left(=E^{\prime}{ }_{450}-E^{\prime}{ }_{510}\right)$ and 0.1 for sample B1, and both are larger than those of the $\alpha_{1}$ absorption. Therefore, for sample B1, the $\alpha_{2}$ absorption can be regarded as the main absorption. The half value width $\Delta T_{1 / 2}$ of the $\tan \delta v s$. $T$ curve for this absorption is larger than $100 \mathrm{~K}$ and is about 3 times larger than those of typical semi-crystalline polymers: e.g., $\Delta T_{1 / 2}=20-70$ degree for poly(ethylene terephthalate). ${ }^{4}$ In a later section, we will show that the $\alpha_{2}$ absorption is not single, but can be separated into two absorptions denoted by $\alpha_{2,1}$ and $\alpha_{2,2}$ from higher temperature side.

The value of $E^{\prime}$ for sample B1 increases with increasing temperature in the temperature range of the $\alpha_{3}$ absorption. The peak value of $\tan \delta$ of this absorption is very small and in the order of 0.05 or less. This increment in $E^{\prime}$ can not be explained by phenomenological equation of rheology because this increment results in negative relaxation intensity.

\section{Mechanism of $\alpha_{3}$ Absorption}

The temperature range covering the $\alpha_{3}$ absorption overlaps completely with that of the mechanical absorption reported by Hatakeyama and Kanetsuna ${ }^{13}$ for a regenerated cellulose solid prepared by saponification of cellulose triacetate. They claimed that the sample was absolutely amorphous and considered that the absorption originated from

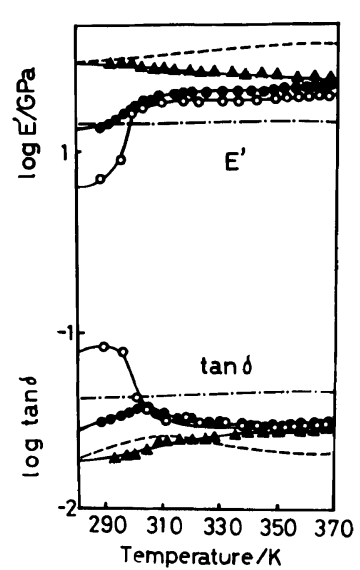

Figure 3. Temperature dependence of $\tan \delta$ and $E^{\prime}$ under the condition of various humidity for sample B2, stored in air with various humidity: Broken line, sample stored in air of $\mathrm{RH}=0 \%$ at $303 \mathrm{~K}$ and measured under air of $\mathrm{RH}=0 \%(303 \mathrm{~K})$; chain line, sample stored in air of $\mathrm{RH}=67 \%$ at $303 \mathrm{~K}$ and measured under air of $\mathrm{RH}=67 \%(303 \mathrm{~K})$; filled circle, sample stored in air of $\mathrm{RH}=60 \%$ at $303 \mathrm{~K}$ and measured under air of $\mathrm{RH}=0 \%$ $(303 \mathrm{~K})$; open circle, sample stored in air of $\mathrm{RH}=80 \%$ at $303 \mathrm{~K}$ and measured under air of $\mathrm{RH}=0 \%(303 \mathrm{~K})$; filled triangle, sample stored in air of $\mathrm{RH}=0 \%$ at $303 \mathrm{~K}$ and measured under air of $\mathrm{RH}=67 \%(303 \mathrm{~K})$.

the micro-Brownian motion of cellulose segment existing in the amorphous region (i.e., $\alpha_{\mathrm{a}}$ absorption or $\alpha$ dispersion). However, the $\alpha_{3}$ absorption can not be interpreted by this mechanism: The moduli $E^{\prime}$ of the cellulose samples exhibiting a distinct $\alpha_{3}$ absorption, say $\mathrm{B} 1, \mathrm{~B} 2, \cdots$, increase with incresing temperature in contrast to the general trend of $E^{\prime}$ in the $\alpha$ dispersion as was observed by Hatakeyama and Kanetsuna. On the other hand, as for the samples which do not exhibit the $\alpha_{3}$ absorption, $E^{\prime}$ decreases with increasing temperature.

Figure 3 shows $E^{\prime} v s . T$ and $\tan \delta$ vs. $T$ curves for sample B2 which was stored in air with various $\mathrm{RH}$ of $0,60,67$, and $80 \%$ until the measurement. Note that humidity of the environmental air during the measurement is different with that of the storage. In this case, the $\alpha_{3}$ absorption peak is observed only when $\mathrm{RH}$ of the sample chamber at $303 \mathrm{~K}$ is less 


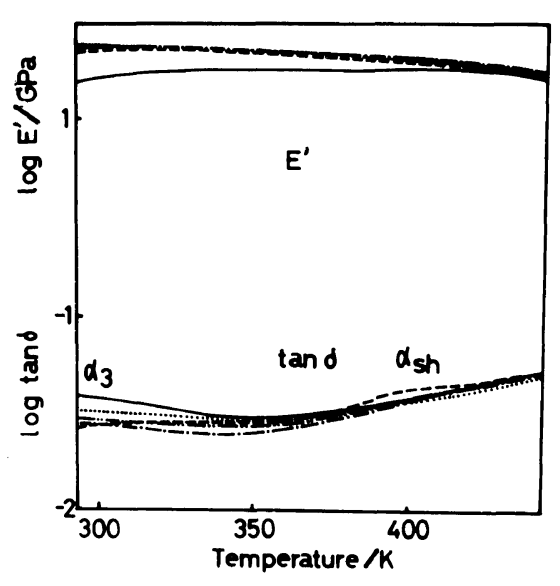

Figure 4. Changes in $\tan \delta v s . T$ and $E^{\prime} v s . T$ curves for sample $B 2$ by heat-treatment: heat-treatment at $383 \mathrm{~K}$ for $30 \mathrm{~s}\left(\mathrm{H}_{383}\right)$; - - - heattreatment at $418 \mathrm{~K}$ for $30 \mathrm{~s}\left(\mathrm{H}_{418}\right)$; - -.- , heattreatment at $438 \mathrm{~K}$ for $30 \mathrm{~s}\left(\mathrm{H}_{438}\right)$; ------, heat-treatment at $458 \mathrm{~K}$ for $30 \mathrm{~s}\left(\mathrm{H}_{458}\right)$.

than that in the storage before the measurement. With an increase in $\mathrm{RH}$ in the storage (i.e., as an increase in water content in the cellulose sample), $\tan \delta$ at $313 \mathrm{~K}$ increases and $E^{\prime}$ at $313 \mathrm{~K}$ decreases. This indicates that water molecules contained in the cellulose solid are closely related to the appearance of the $\alpha_{3}$ absorption (hereafter referred to as $\alpha_{\mathrm{H}_{2} \mathrm{O}}$ absorption).

Figure 4 shows the temperature dependence of $\tan \delta$ and $E^{\prime}$ for sample B2 which were annealed at various temperatures $\left(T_{\mathrm{a}}\right)$ for $30 \mathrm{~s}$, followed by quenching at $293 \mathrm{~K}$ with dry air under the fixed length (newly, referred to as $\mathrm{H}_{383}, \mathrm{H}_{418}, \mathrm{H}_{438}$, and $\mathrm{H}_{458}$ ). The water regain of these samples, evaluated from the change in weight of the samples before and after the heat-treatment at $403 \mathrm{~K}$, was always less than $1 \%$. For samples $\mathrm{H}_{418}, \mathrm{H}_{438}$, and $\mathrm{H}_{458}$, the $\alpha_{\mathrm{H}_{2} \mathrm{O}}-\tan \delta$ peak disappears, and $\tan \delta$ at $313 \mathrm{~K}$ decreases with an increase in $T_{\mathrm{a}}$. This does not mean that the $\alpha_{\mathrm{H}_{2} \mathrm{O}}$ absorption disappears due to some probable change in supermolecular structure brought about by annealing. We confirmed in other experiments not shown here that for regenerated cellullose samples, absolutely dried in vacuum without annealing, the $\alpha_{\mathrm{H}_{2} \mathrm{O}}$ absorption was not also observed.

The experimental facts shown in Figures 3 and 4 suggest strongly that the absorption of water molecule into sample is the main factor contributing to the appearance of the $\alpha_{\mathrm{H}_{2} \mathrm{O}}$ absorption. That is, the $\alpha_{\mathrm{H}_{2} \mathrm{O}}$ absorption may not be due to the inherent molecular motion of the segments in the regenerated cellulose solid, but due to the cooperative motion of cellulose chain segments and water molecules absorbed. It may be reasonable to assume that water molecules penetrate preferentially into a part of an amorphous region consisting of loosely packed chain molecules as in the case of Nylon $66 .^{23}$ Water molecules absorbed in the cellulose solid make the local viscosity around the chain segment small, giving rise to shortening the relaxation time of the segmental motion. Consequently, the cooperative motion of the polymer segments and water molecule displays an absorption in the lower temperature side than does the micro-Brownian motion of the water-free cellulose chain.

When a part of water molecules absorbed in the sample evaporates during the measurement, the relaxation time increases, resulting in an increase in $E^{\prime}$ as is shown in Figure 3. Then, the mechanical absorption, determined by Hatakeyama and Kanetsuna, ${ }^{13}$ due to the micro-Brownian movement of cellulose chain segment in amorphous region may not correspond to $\alpha_{\mathrm{H}_{2} \mathrm{O}}$ although the peak temperature locates near to that of $\alpha_{\mathrm{H}_{2} \mathrm{O}}$, but corresponds to $\alpha_{\mathrm{sh}}$ as will be discussed below.

\section{Mechanisms of $\alpha_{\mathrm{sh}}$ and $\alpha_{2}$ Absorption}

Figure 5 shows the $\tan \delta v s . T$ and $E^{\prime \prime} v s . T$ curves in the temperature range from 350 to $550 \mathrm{~K}$ for sample $\mathrm{T} 1$ measured at the frequencies of 110,11 , and $3.5 \mathrm{~Hz}$. When the frequency of 11 or $3.5 \mathrm{~Hz}$ is used, the peak of the $\alpha_{2}$ absorption observed in both of $\tan \delta v s . T$ and $E^{\prime \prime}$ vs. $T$ curves at $110 \mathrm{~Hz}$ splits into two peaks. This means that the $\alpha_{2}$ absorption 

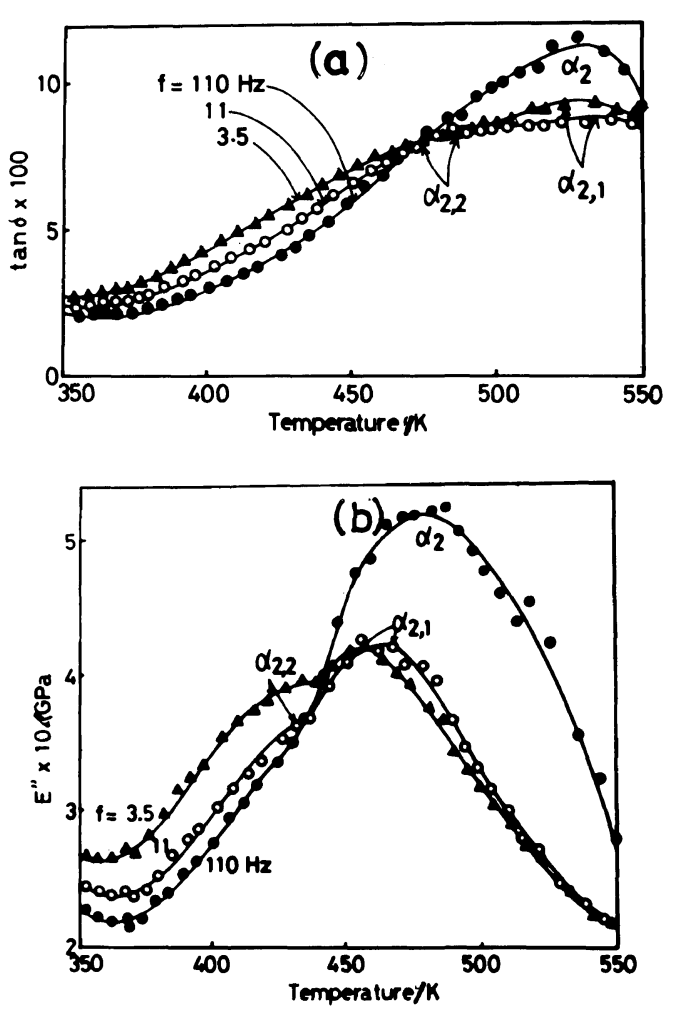

Figure 5. Tan $\delta$ vs. $T$ and $E^{\prime \prime} v s$. $T$ curves for sample $\mathrm{T} 1$ at the frequencies of 110,11 , and $3.5 \mathrm{~Hz}$ : (a), $\tan \delta v s$. $T$ curve; (b), $E^{\prime \prime}$ vs. $T$ curve.

consists of two different absorptions: $\alpha_{2,1}$ and $\alpha_{2,2}$. The peak temperatures of $\tan \delta$ and $E^{\prime \prime}$ were evaluated by separating the absorption into $\alpha_{2,1}$ and $\alpha_{2,2}$ absorptions. The relationship between the peak temperature of $E^{\prime \prime}$ for these two absorptions and the frequency $f$ is given in Figure 6. $\Delta H_{\mathrm{a}}$ can be evaluated from the slope of the plot of $\log f v s .1 / T$ in the figure (see eq 1) to be 289 and $209 \mathrm{~kJ} \mathrm{~mol}^{-1}$ for the $\alpha_{2,1}$ and the $\alpha_{2,2}$ absorptions, respectively. These values lie in the range from 146 to $669 \mathrm{~kJ} \mathrm{~mol}^{-1}$, in which all $\Delta H_{\mathrm{a}}$ values experimentally determined for the micro-Brownian motion of polymer segments in an amorphous region. ${ }^{4}$ In other words, both the $\alpha_{2,1}$ and the $\alpha_{2,2}$ absorptions are caused by the micro-Brownian motion of the polymer chain segments in the amorphous region. Both of the $\Delta H_{\mathrm{a}}$ values for the $\alpha_{2,1}$ and $\alpha_{2,2}$ absorptions are smaller

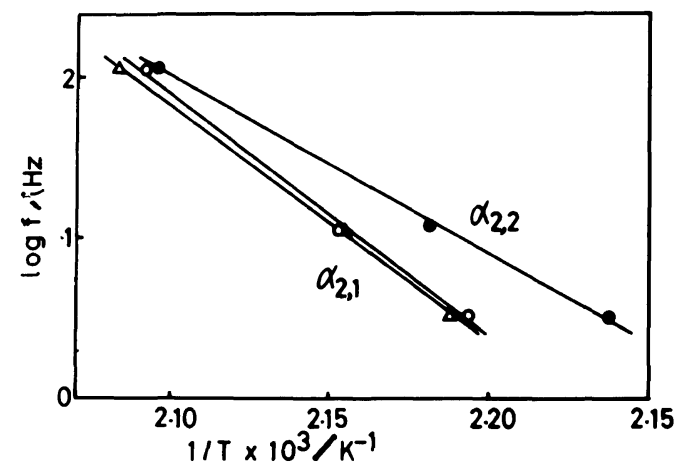

Figure 6. Plots of frequency and the reciprocal peak temperature of $\alpha_{2,1}$ and $\alpha_{2,2}$ absorptions: Filled circle, peak temperature of $E^{\prime \prime}$ of the $\alpha_{2,2}$ absorption; open circle, peak temperature of $E^{\prime \prime}$ of the $\alpha_{2,2}$ absorption; open triangle, peak temperature of $\tan \delta$ of the $\alpha_{2,1}$ absorption.

than that of the $\alpha_{1}$ absorption given in the later section.

The magnitude of the relaxation time and the apparent activation energy of the $\alpha_{a} a b-$ sorption change depending on the segmental environment such as packing regularity and packing density of chain segments. The splitting of the $\alpha_{\mathrm{a}}$ absorption into the two absorptions $\left(\alpha_{2,1}\right.$ and $\left.\alpha_{2,2}\right)$ may be caused by the existence of two distinguished segmental environments in the amorphous region.

Figure 7 shows the effect of annealing temperature on $\tan \delta$ vs. $T$ curve for cellulose. By annealing at temperature above $483 \mathrm{~K}$, the $\alpha_{2,2}$ absorption disappears and the $\alpha_{2,1}$ absorption shifts significantly to higher temperature side in $\tan \delta v s$. $T$ curve accompanying with a new shoulder at the temperature range between $413 \mathrm{~K}$ and $473 \mathrm{~K}$.

The peak temperature of $\tan \delta$ of the $\alpha_{2,1}$ absorption, $T_{\max 2,1}$, the peak value $(\tan \delta)_{\max 2,1}$ and the shoulder temperature $T_{\text {sh }}$ for sample $\mathrm{H} 1, \mathrm{H} 2, \mathrm{H} 3, \mathrm{H} 4$, and $\mathrm{H} 5$ are plotted against the annealing temperature $T_{\mathrm{a}}$ in Figure 8. In the range of $T_{\mathrm{a}}>498 \mathrm{~K}$, dependence of $T_{\max 2,1}$ and $T_{\mathrm{sh}}$ on annealing temperature $T_{\mathrm{a}}$ can be empirically expressed as; $T_{\max 2,1}=T_{\mathrm{a}}+15(\mathrm{~K})$ and $T_{\mathrm{sh}}=T_{\mathrm{a}}-80(\mathrm{~K})$. 


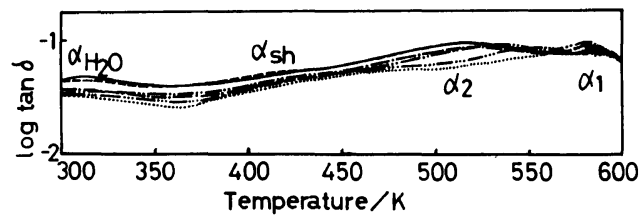

Figure 7. Temperature dependence of $\tan \delta$ for samples of $\mathrm{H}$ series:,$- \mathrm{B} 2 ;----, \mathrm{H}_{468} ;---, \mathrm{H}_{493}$; ,$---- \mathrm{H}_{513} ;-----, \mathrm{H}_{535} ;-----, \mathrm{H}_{548}$.

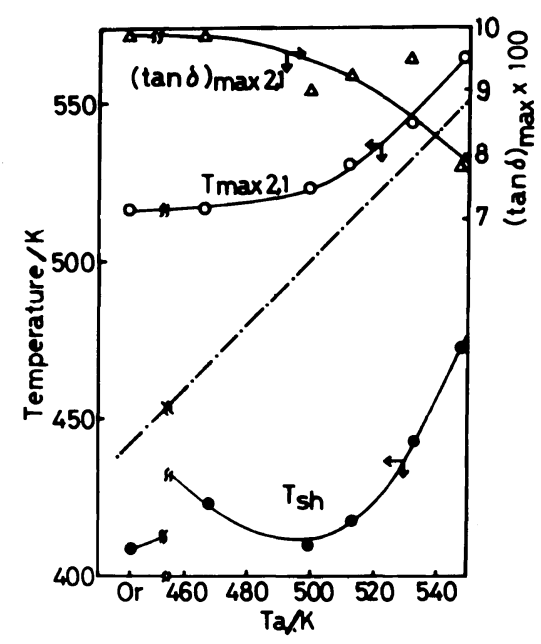

Figure 8. Changes in $T_{\max 2,1}, T_{\mathrm{sh}}$, and $(\tan \delta)_{\max 2,1}$ with annealing temperature $T_{\mathrm{a}}$ for samples of $\mathrm{H}$ series: Chain line indicates the relation of $T_{\max }=T_{\mathrm{a}}$ and (Or) indicates sample B2.

The shoulder of $\tan \delta$ located near $423 \mathrm{~K}$ moves toward high temperature side with elevating $T_{\mathrm{a}}$ in the manner similar to the $\alpha_{2,1}$ absorption. This means that the shoulder is attributable to the same kind of molecular motion of the $\alpha_{2,1}$ absorption: that is, segmental micro-Brownian motion. On the other hand, the characteristic values relating to the crystalline region such as $L_{10 \overline{1}}, L_{002}$, and $\chi_{\mathrm{c}}$ cited in Table I change only slightly with elevating $T_{\mathrm{a}}$. We can conclude that the rearrangement of molecular packing in the amorphous region occurs without a growth of crystalline region.

Figure 9 shows plots of $T_{\max 1}, T_{\max 2,2}$, and $T_{\text {sh }}$ against $T_{\max 2,1}$ for all the samples employed. All the samples do not always show all

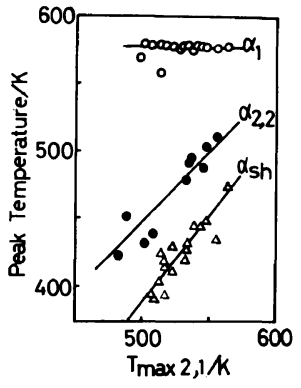

Figure 9. Plots of $T_{\max 1}, T_{\max 2,2}$, and $T_{\mathrm{sh}}$ against $T_{\max 2,1}$.

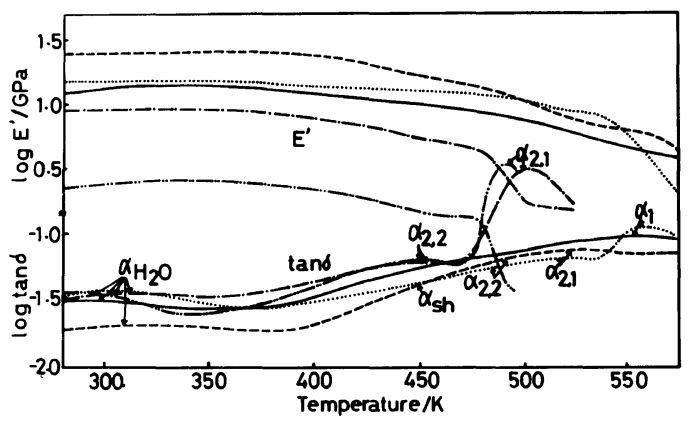

Figure 10. Temperature dependence of $E^{\prime}$ and $\tan \delta$ for the regenerated cellulose fibers and membranes: - BH1: ----, B3; --_, T2; --._, T3; -----, B4.

four absorptions $\alpha_{1}, \alpha_{2,2}, \alpha_{\text {sh }}$, and $\alpha_{2,1}$ simultaneously. There is a linear relationship between $T_{\max 2,2}$ or $T_{\mathrm{sh}}$ and $T_{\max 2,1}$, but $T_{\max 1}$ is independent of $T_{\max 2,1}$.

The temperature dependence of $E^{\prime}$ and $\tan \delta$ for the regenerated cellulose fibers (sample B3, $\mathrm{B} 4$, and $\mathrm{BH} 1$ ) and membranes (sample $\mathrm{T} 2$ and T3) are shown in Figure 10. All mechanical absorptions cited in this figure are named tentatively on the basis of the following procedure. When $\Delta H_{\mathrm{a}}$ for the absorption in question is larger than $627 \mathrm{~kJ} \mathrm{~mol}^{-1}$, the absorption is named as $\alpha_{1}$ absorption, and when $\Delta H_{\mathrm{a}}$ is smaller than $418 \mathrm{~kJ} \mathrm{~mol}^{-1}$ and larger than $125 \mathrm{~kJ} \mathrm{~mol}^{-1}$, the absorption is named as the $\alpha_{2}$ absorption. $T_{\max }$ of the $\alpha_{2}$ absorption scatters over the wide temperature range between $453 \mathrm{~K}$ and $543 \mathrm{~K}$. It can be concluded from Figure 10 that when the cellulose solids are solidified from the cellulose solution with 

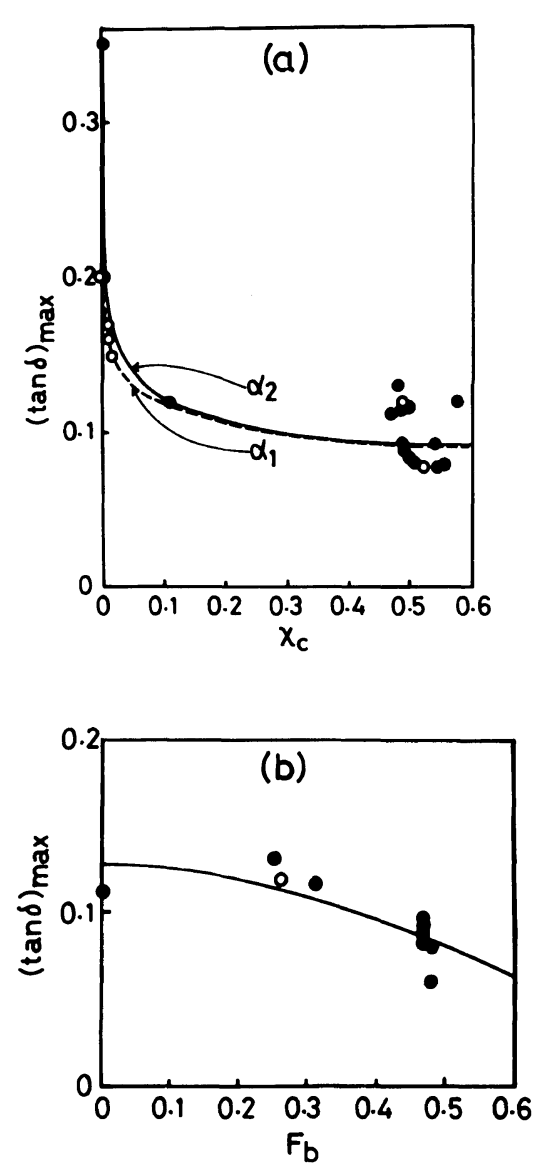

Figure 11. Dependence of peak value of $\tan \delta$, (tan $\delta)_{\max }$ of $\alpha_{1}$ and $\alpha_{2}$ absorptions on $\chi_{\mathrm{c}}$ and $F_{\mathrm{b}}$ : Filled circle, $\alpha_{1}$ absorption; open circle, $\alpha_{2}$ absorption. (a), $\chi_{\mathrm{c}}$ dependence; (b), $F_{\mathrm{b}}$ dependence.

some organic solvent such as acetone (for example, sample T2 and T3), the $\tan \delta$ vs. $T$ curve of the solid varies drastically its shape and the peak temperature.

Figure 11 shows the plots of $(\tan \delta)_{\max }$ of the $\alpha_{2}$ and the $\alpha_{1}$ absorptions against $\chi_{\mathrm{c}}$ for the sample with various $F_{\mathrm{b}}$, and against $F_{\mathrm{b}}$ for the sample with $\chi_{c}$ of 0.475 and 0.522 . The data points in Figure 11 are selected only for the sample that shows distinctly the peak of the $\alpha_{2}$ or $\alpha_{1}$ absorption.

The value of $(\tan \delta)_{\max }$ of the $\alpha_{1}$ and the $\alpha_{2}$ absorption decreases with an increase of $\chi_{c}$ indicating that both absorptions are originated by the thermal motion of the segments in noncrystalline region. When $F_{\mathrm{b}}$ increases, $(\tan \delta)_{\max }$ tends to decrease in the case of the $\alpha_{2}$ absorption.

\section{Mechanism of $\alpha_{1}$ Absorption}

Usually, $T_{\max 1}$ is too high to measure the whole absorption profile in air without any kinds of chemical degradation. It is, therefore, necessary to ascertain in advance whether or not the $\tan \delta$ peak phenomenologically observed near $573 \mathrm{~K}$ is due to any chemical degradation and is erroneously assigned to the $\alpha_{1}$ absorption. If it is so, $\Delta H_{\mathrm{a}}$, defined by eq 1 , is theoretically predicted to be infinitely large, because the initiation temperature and the rate of the chemical degradation reaction should be independent of measuring frequency $f . \Delta H_{\mathrm{a}}$, experimentally estimated for the $\alpha_{1}$ absorption of cellulose solids, scattered widely in the range $1050-1470 \mathrm{~kJ} \mathrm{~mol}^{-1}$, but did never exceed $1670 \mathrm{~kJ} \mathrm{~mol}^{-1}$ and an average value was $1210 \mathrm{~kJ} \mathrm{~mol}^{-1}$. Thus, we concluded that the socalled $\alpha_{1}$ absorption observed in this article did not originate from chemical degradation. In other words, the possibility of an erroneous assignment against the $\alpha_{1}$ absorption is definitely denied. $\Delta H_{\mathrm{a}}$ for the $\alpha_{1}$ absorption is significantly outside of the range 147$670 \mathrm{~kJ} \mathrm{~mol}^{-1}$, being characteristic to the $\alpha_{\mathrm{a}}$ absorption. Even in the amorphous region, a portion of cellulose chains builds up to large extent intra- and intermolecular hydrogen bonds, which may make the occurrence of the micro-Brownian motion difficult at lower temperature and in consequence makes $\Delta H_{\mathrm{a}}$ large. Then, the value of $\Delta H_{\mathrm{a}}$ does not always deny that the $\alpha_{1}$ absorption belong to the $\alpha_{\mathrm{a}}$ absorption. $T_{\max 1}$ is expected to be lowered by adding solvents such as water, acting as a plasticizer to cellulose solid, if the $\alpha_{1}$ absorption can be assigned to another $\alpha_{\mathrm{a}}$ absorption.

In Figure 12 is shown the plots of $\log E^{\prime}$ and $\tan \delta$ against $T$ for sample B2 dipped in water or placed under air with various $\mathrm{RH}$. With an 
increase in $\mathrm{RH}, E^{\prime}$ decreases monotonically in the range 278 and $343 \mathrm{~K}$. This indicates a plasticizing effect of water molecule on the cellulose solid. At $\mathrm{RH}=100 \%$, the dynamic dispersion of $E^{\prime}$ is observed at about $313 \mathrm{~K}$ and $E^{\prime}$ decreases from $8 \mathrm{GPa}$ at $293 \mathrm{~K}$ to 2 $\mathrm{GPa}$ at $343 \mathrm{~K}$ with increasing temperature. The former value is equivalent with $E^{\prime}$ at $523 \mathrm{~K}$ measured in dry air and the latter value is the same as that at $573 \mathrm{~K}$ in dry air. Therefore, we can conclude that the dynamic dispersion near $313 \mathrm{~K}$ in the atmosphere of $\mathrm{RH}=100 \%$ is attributed to the $\alpha_{1}$ absorption, usually observable near $573 \mathrm{~K}$ in dry air. Corresponding to this dispersion of $E^{\prime}$ at $\mathrm{RH}=100 \%, \tan \delta$ attains maximum, showing a peak, at the sample temperature near $313 \mathrm{~K}$ as shown in Figure 12b. Of course, this $\tan \delta$ peak is due to the $\alpha_{1}$ absorption. When the cellulose solid is immersed in water, the $\alpha_{1}$ absorption shifts to lower temperature than $303 \mathrm{~K}$.

Figure 13 shows the plots of $\tan \delta$ at $573 \mathrm{~K}$, $\tan \delta_{573}$, against the degree of crystal orientation $F_{\mathrm{b}}$ for samples of $\mathrm{B}, \mathrm{T}$, and $\mathrm{BH}$ series. Here, $\tan \delta_{573}$ reflecting the absorption intensity of the $\alpha_{1}$ absorption decreases monotonously with $F_{\mathrm{b}}$. This means that the value of $E^{\prime}$ after the $\alpha_{1}$ absorption is governed by the orientation of crystalline. By taking into account the experimental results of $\chi_{c}$ dependence of $(\tan \delta)_{\max }$ (Figure 11) and of the change of $T_{\max }$ with water absorption content (Figure 12), and of $F_{\mathrm{b}}$ dependence of $\tan \delta_{573}$ (Figure 13), we can conclude that the molecular chain in the crystalline region does not contribute to the $\alpha_{1}$ absorption.

Water molecules can not penetrate into the crystalline region under the normal pressure at temperature below $373 \mathrm{~K}$ and may not go into the non-crystalline region composing of the extended chain molecules such as those in microfibrils proposed by Prevorsek ${ }^{24}$ for poly(ethylene terephthalate) fiber. $E^{\prime}$ of the regenerated cellulose fiber at $303 \mathrm{~K}$ in water (ca. $2 \mathrm{GPa}$ ) is much larger than $E^{\prime}$ at tempera-
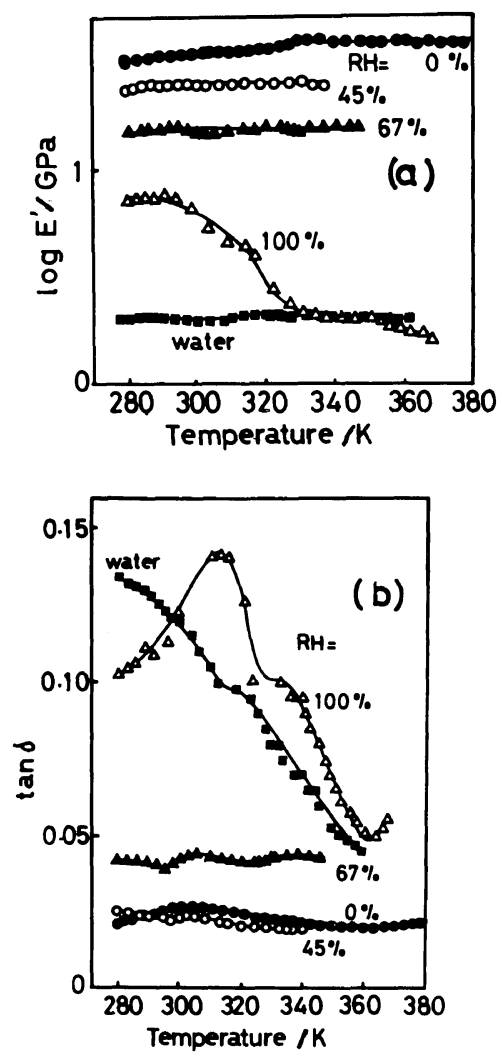

Figure 12. Changes in the $\log E^{\prime} v s . T$ and $\log \tan \delta v s$. $T$ curves for sample B2 with the content of water in environmental air: (a), $\log E^{\prime}$ vs. temperature curve; (b), $\log \tan \delta v s$. temperature curve; $\mathrm{RH}$ indicates relative humidity and water indicates that the measurement was carried out in water.

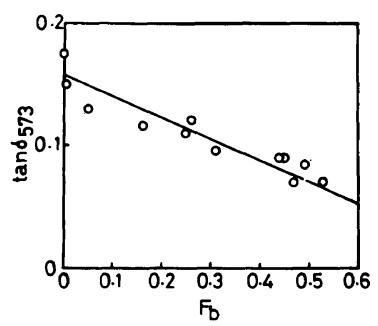

Figure 13. Dependence of $\tan \delta$ value at $573 \mathrm{~K}$ on the orientation function parameter of $b$ axis $F_{\mathrm{b}}$ for samples of $\mathrm{B}, \mathrm{T}$, and $\mathrm{BH}$ series.

ture higher than the $\alpha_{\mathrm{a}}$ absorption of synthetic fibers.

The curves of $\tan \delta v s . T$ and $E^{\prime} v s . T$ are 


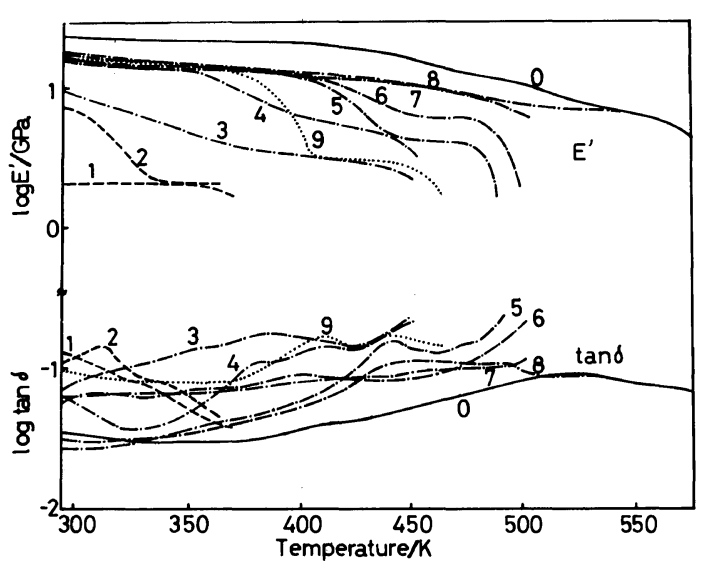

Figure 14. Temperature dependence of $\tan \delta$ and $E^{\prime}$ in the environments with various solvents for sample B2: 0 , dry air; $1, \mathrm{H}_{2} \mathrm{O} ; 2$, air with $100 \% \mathrm{RH} ; 3$, ethylene glycol; 4, diethylene glycol; 5, triethylene glycol; 6, poly(ethylene glycol) $(\mathrm{MW}=200) ; 7$, poly(ethylene glycol) $(\mathrm{MW}=400) ; 8$, poly(ethylene glycol) $(\mathrm{MW}=600), 9$, glycerin.

generally expected to shift to lower temperature side when the sample is measured in liquids having thermodynamic affinity with cellulose. Figure 14 shows the experimental results measured for sample B2 in various solvents. With increasing the ratio of the sum of the molecular weight of all hydroxyl groups in a solvent molecule to the total molecular weight of the solvent molecule (i.e., the hydroxyl group density), $E^{\prime}$ at $T_{\max }$ decreases and $T_{\max }$ shifts to lower temperature side. This strongly suggests that solvent molecules having higher hydroxyl group density can penetrate more easily into the amorphous region of cellulose. It was experimentally confirmed that the amount of shifting of $T_{\max }$ by plasticizer effect increases with the solvent content in the sample solid. Therefore, from the amount of shifting determined for each absorption $\alpha_{1}, \alpha_{2,1}, \alpha_{2,2}$, and $\alpha_{\mathrm{sh}}$ from Figure 14, we can estimate roughly the content of the solvent absorbed in the region relating to each absorption. The results show that the solvent molecule can penetrate more easily into the amorphous region composed of loosely-packed molecular chains than into the closely packed region.

In summary, regenerated cellulose solids reveal the five kinds of mechanical absorptions originated from micro-Brownian movement of molecular chains in amorphous phase: $\alpha_{\mathrm{H}_{2} \mathrm{O}}$, $\alpha_{\mathrm{sh}}, \alpha_{2,2}, \alpha_{2,1}$, and $\alpha_{1}$. From the view point that micro-Brownian movement gives one glass transition, ${ }^{25}$ the regenerated cellulose solid has five glass transition temperatures. From this, we may conclude that there are five kinds of amorphous phases having size at least larger than $10 \times 10 \times 10\left(\mathrm{~nm}^{3}\right)$ of moving chain segment. ${ }^{25}$ The above complexity of the amorphous phase is intimately correlated with intra- and intermolecular hydrogen bondings as revealed from the behaviors of the viscoelasticity in the solvent with hydroxyl groups shown in Figure 14.

It might be oversimplified to consider that the viscoelastic absorptions have one-to-one correspondence to the intra- and intermolecular hydrogen bondings existing in the amorphous phase. These can be regarded as fundamental structural elements, because the body responsible for the viscoelastic absorption is a mixture of fundamental structural elements. The five amorphous phases may differ in the mixing compositions of the elements. For simplicity, We can speculate as follows: The $\alpha_{\mathrm{H}_{2} \mathrm{O}}$ absorption corresponds to the cooperative motion of cellulose chains and water molecules in the amorphous region, in which intra- and intermolecular hydrogen bondings are almost completely destroyed. The $\alpha_{2}$ absorption is due to the microBrownian movement of cellulose chains in the amorphous region, in which intra- and intermolecular hydrogen bondings are completely $\left(\alpha_{\text {sh }}\right.$ and $\left.\alpha_{2,2}\right)$ or partially $\left(\alpha_{2,1}\right)$ destroyed. Careful examination of the detailed structure of ${ }^{13} \mathrm{C}$ NMR spectra of $\mathrm{C}_{4}$ carbon peak region (see Figure 7 of ref 1a) shows that the strength of intramolecular hydrogen bonding, as evaluated by $\mathrm{CP} / \mathrm{MASS}{ }^{13} \mathrm{C} \mathrm{NMR}$ spectra, varies usually to a large extent within a given regenerated cellulose solid, if the solid 
Table II. Dynamic mechanical absorptions observed for regenerated cellulose solids in the range from 280 to $600 \mathrm{~K}$

\begin{tabular}{|c|c|c|c|c|}
\hline Absorption & $\begin{array}{c}\text { Temperature } \\
\text { range of } \\
T_{\max } / \mathrm{K}\end{array}$ & $\begin{array}{c}\Delta H_{\mathrm{a}} / \\
\mathrm{kJ} \mathrm{mol}^{-1}\end{array}$ & Mechanism & $\begin{array}{l}\text { Assignment of the region } \\
\text { responsible for the absorption }\end{array}$ \\
\hline$\alpha_{1}$ & $558-578$ & 1210 & $\begin{array}{l}\text { Micro-Brownian motion } \\
\text { of segments in } \\
\text { amorphous region }\end{array}$ & $\begin{array}{l}\text { Amorphous region with strong } \\
\text { intra- and intermolecular } \\
\text { hydrogen bonds }\end{array}$ \\
\hline$\alpha_{2,1}$ & $488-563$ & 289 & Ditto & Amorphous region separated \\
\hline$\alpha_{2,2}$ & $413-513$ & 209 & Ditto & $\begin{array}{l}\text { of polymer segments with mode- } \\
\text { rately developed intra- and }\end{array}$ \\
\hline$\alpha_{\mathrm{sh}}$ & $388-473$ & a & & intermolecular hydrogen bonds \\
\hline$\alpha_{\mathrm{H}_{2} \mathrm{O}}$ & $303-323$ & a & $\begin{array}{l}\text { Cooperative motion } \\
\text { of sorbed } \mathrm{H}_{2} \mathrm{O} \text { and } \\
\text { segments in } \\
\text { amorphous region }\end{array}$ & $\begin{array}{l}\text { Amorphous region without intra- } \\
\text { intermolecular hydrogen bonds, } \\
\text { and partially plasticized with } \\
\text { water }\end{array}$ \\
\hline
\end{tabular}

a Not evaluated because of difficulty to determine $T_{\max }$ accurately.

is not treated under specific conditions. The distribution of the intramolecular hydrogen bond strength may bring about the $\alpha_{2}$ absorption with multiple peaks. The $\alpha_{1}$ absorption corresponds to the molecular motion of cellulose chains belonging to the amorphous region, in which intra- and intermolecular hydrogen bondings are strongly and densely formed, and this can explain an extraordinary large $\Delta H_{\mathrm{a}}$ for the $\alpha_{1}$ absorption. The assignment of these absorptions is summarized in Table II.

The more quantitative evaluation, by using Manabe-Kamide method, ${ }^{8}$ of the supermolecular structure of the amorphous region, corresponding to the $\alpha_{2}$ absorption, will be presented in a forthcoming paper.

\section{REFERENCES}

1. See for example, a) K. Kamide, K. Okajima, T. Matsui, and K. Kowsaka, Polym, J., 16, 857 (1984); b) K. Kamide, K. Okajima, K. Kowsaka, and T. Matsui, Polym. J., 17, 701 (1985); c) K. Kamide, K. Kowsaka, and K. Okajima, Polym. J., 17, 707 (1985).

2. See for example, J. Brandrup and E. H. Immergut, Ed., "Polymer Handbook," 2nd ed, Jon Wiley \&
Sons, Inc., New York, N. Y., 1975, P. V-90.

3. See for example, H. Maeda, Sen-i Gakkaishi, 12, 6 (1956).

4. S. Manabe, K. Kamide, and C. Nakayama, J. Text. Mach. Soc. Jpn., 30, T45 (1977).

5. S. Manabe, K. Kamide, and C. Nakayama, J. Text. Mach. Soc. Jpn., 30, T55 (1977).

6. S. Manabe, K. Kamide, and C. Nakayama, J. Text. Mach. Soc. Jpn., 30, T66 (1977).

7. S. Manabe, K. Kamide, C. Nakayama, and S. Kobayashi, J. Text. Mach. Soc. Jpn., 30, T85 (1977).

8. S. Manabe and K. Kamide, Polym. J., 16, 375 (1984).

9. J. Kubat and P. Pattyramie, Nature, 215, 390 (1967).

10. P. M. Haughton and D. B. Sellen, J. Phys. D. Appl. Phys., 6, 1998 (1973).

11. See for example, M. Wabba and K. Asiz, J. Text. Inst., 53, 291 (1962).

12. See for example, O. V. Klotnikov, A. I. Mikhailov, and E. L. Rayavee, Vysokomol. Soyedin. Ser., A, 19, 2528 (1977).

13. T. Hatakeyama and H. Kanetsuna, Kobunshi Kagaku, 26, 76 (1969).

14. M. V. Ramiah and D. A. I. Goring, J. Polym. Sci., C, No. 11, 27 (1965).

15. K. Nakamura, Kobunshi Kagaku, 13, 47 (1956).

16. K. Nakamura, Kobunshi Kagaku, 14, 544 (1957).

17. K. Kamide and M. Saito, Polym. J., 17, 919 (1985).

18. Asahi Chemical Ind. Co., Japan Open Patent 5599926 (1980).

19. Asahi Chemical Ind. Co., Japan Open Patent 5889625 (1983).

20. S. Manabe, M. Iwata, K. Kamide, Polym. Prepr. 
S. Manabe, M. Iwata, and K. Kamide

Jpn., 31, 802 (1982).

21. M. Iwata, S. Manabe, and K. Kamide, unpublished work.

22. S. Manabe, S. Kajita, and K. Kamide, J. Text. Mach. Soc. Jpn., 34, T98 (1981).

23. C. Nakayama, K. Kamide, S. Manabe, and M. Hara,
Sen-i Gakkaishi, 33, T-281 (1977).

24. D. Prevorsek and R. H. Butler, Int. J. Polym. Mater., 1, 251 (1972).

25. C. Nakayama, K. Kamide, S. Manabe, and T. Samamoto, Sen-i Gakkaishi, 35, T-139 (1977). 